\title{
A Fulbright Scholar's Experience: Irish Nursing Education History and Change via Curriculum and Staff Development Perspectives
}

\author{
Virginia Fitzsimons ${ }^{1 *}$ and Sylvia Huntley Moore ${ }^{2}$ \\ ${ }^{1} R N C$, EdD, FAAN, Professor, School of Nursing Kean University, Union, New Jersey, USA \\ ${ }^{2}$ BA Dip Ed Med, Director Staff Education and Development School of Nursing and Midwifery Trinity College, University of Dublin, Ireland
}

Submission: May 09, 2018; Published: May 17, 2018

*Corresponding author: Virginia Fitzsimons, RNC, EdD, FAAN, Professor, School of Nursing Kean University, Union, New Jersey, USA,

Email: dr.virginiafitzsimons@gmail.com

\begin{abstract}
In 2002, pre-registration nurse education in the Republic of Ireland moved from a hospital-based apprenticeship system to third level institutions. Such a major historical event warrants attention and review. Fitzsimons and Huntley-Moore served as a team for change. The United States Fulbright Commission funded a New Jersey-based nursing faculty member to serve as a Curriculum Consultant and lecturer at Trinity College in Dublin, Ireland to assist the nursing faculty to develop its first baccalaureate curriculum, unique to Ireland. From 2015 to the present time, such consultations and lecturing has continued serving four of the leading nursing programs in Ireland. Implications of change of scope of practice, in particular the need for major curriculum development including the articulation of learning outcomes, instructional methods and assessment strategies are highlighted. In turn, such a change required substantial professional development to meet the needs of nurse lecturers as they adapted to the role changes and the new competencies inherent in the process.
\end{abstract}

Keywords: Fulbright Scholar; Diploma program; Baccalaureate curriculum; Irish Nursing

\section{Introduction}

This paper aims to describe the national and international contexts of this move and to predict nursing practice for the future which arises from the guidelines of An Bord Altranais. New descriptions of the role of the nurse and the demands of research and evidence-based practice shape the development of the evolving curricula as undergraduate nurse education moved from hospital-based programs to higher education settings, specifically universities and institutes of technology. Bound up with this process, was the changing role of the nurse lecturer in the new educational setting. As other countries introduce degree level education as the standard for nurse preparation they will use their own cultural contexts to interpret nursing standards for their own populations. The United Kingdom, Australia and the United States, among others, have made such a shift. And, in the end, one or a number of good practice models or blueprints will emerge. This paper describes the journey of one university-based, School of Nursing in the Republic of Ireland. This is a historical moment which warrants documentation for Irish history and can serve as a nursing educational model for others. "One day Alice came to a fork in the road and saw a Cheshire cat in a tree. Which road do I take? She asked. Where do you want to go? Was his response. I don't know, Alice answered. Then, said the cat, it doesn't matter".

\section{Lewis Carroll}

“How do you know to get there, if you don't know where you want to go?"

\section{Mildred Montag}

For a long time international nursing had been struggling with a fundamental tension in relation to the preparation of nurses for clinical practice. Recruitment and retention concerns pointed to difficulties often faced by newly qualified nurses as they attempt to function effectively in a complex and constantly changing health care setting. This was a concern of the Irish Nursing and Midwifery Council [1] who serves as a board of nursing for Ireland. Historical reports from the United Kingdom and the United States [2] identify potential problems when expectations of the hospitals and other health care agencies require complex curriculum changes which alter the nature of the work environment for nurse tutors (faculty). In the United States, for example, it has taken four decades to effect substantial change in nurse education to the point where most nurses are now prepared in colleges and universities. Hospitals strongly resisted closing their schools of nursing because they saw the schools as a pool for staff nurse employees and nurse tutors without doctoral preparation feared 
losing their jobs if the hospital school closed. It was a forty year struggle which left many bad feelings on all sides [2,3].

Australia and the United Kingdom faced similar challenges making the transition to collegiate nurse education. These countries are addressing the challenges of opening higher education to nurse preparation through various plans such as the introduction of cadet schemes, part-time routes and the elimination of specific educational requirements for entry into pre-registration nursing. The experience in the Republic of Ireland (ROI) has been unique. Here, many difficulties were avoided by moving very quickly into higher education once it was decided that the baccalaureate degree should be the entry credential for professional practice.

Pre-registration (licensure) nurse education moved into higher education within a four year period (Report of the Commission On Nursing, 1998). All diploma schools of nursing were closed simultaneously, and consolidated into programs at colleges across the ROI. And perhaps most importantly, on the basis of the Commission's recommendations, Masters qualified nurse tutors were offered tenured, lecturer posts in participating universities and institutes of technology. Those who were not suitably qualified for employment within the established academic career pathway were to be supported by the health service providers to upgrade their educational qualifications to the required level. Taken in their entirety, the Commission's recommendations were instrumental in avoiding a protracted struggle. This paper is a case study which relates how one university faired during the transition time in curriculum development and what educational support systems proved useful to the staff. This experience can serve as a model for others considering such a move and as they explore the needs of faculty in curriculum development.

\section{University Nurse Education}

The period of dramatic, rapid and substantial change in nurse education in the Republic of Ireland has been both exciting and stressful and was initiated by events which led in to the Report of the Commission on Nursing [4]. The document stated that preregistration nursing education should be based on a four year degree program housed in third-level institutions within five years. This journey from a one-hundred and forty year tradition of hospital-based nurse education to third-level was a fundamental and major paradigm shift. As we at Trinity started, the nurse lecturers and administrative staff knew that they were beginning an important journey. Two years into the program, we took stock of our situation and took the time to assess how far we had come and to determine what else had to be accomplished.

\section{The New Curriculum Focus}

Underpinning the development of the curriculum were standards and requirements set by An Bord Altranais, the Irish nurse registration board, which we believe, describe a very contemporary and future-focused infrastructure for nursing services in Ireland. In concert with this framework, substantial work was accomplished with partners from associated hospitals and other agencies to develop curriculum for the new Bachelor of Science degree. Critical thinking and evidence-based practice were identified as the central organizing framework for the curriculum. Historically, the mission of acute care hospitals is care of the sick. Universities on the other hand, focus squarely on generation of knowledge through research and publications. This knowledge is disseminated to undergraduate and post-graduate students, the professional field and the general public. Consequently, nurse tutors found themselves in this dichotomy of focus as they moved from hospital employees to university scholar teachers. It is not an easy leap. These fundamental changes in purpose and focus gave rise to a need for redefinitions of the mission of nursing education because of the change in venue of that education. Of principle importance, was the acknowledgement _that the primary stakeholder in this new educational format was the public of Ireland. Therefore, both the institutions and the professionals involved kept the advancement of nursing standards for the health of the Irish people, and the central goal and focus of accountability in practice, as the journey's destination and the fuel for all our endeavors.

\section{The Emergence of the Teacher Scholar}

Working closely with School staff, we witnessed the beginning of the nurse tutors' evolution to scholar-teachers. With this evolution in mind, we found the development of a significant professional development focus within the curriculum development project. The range of issues surrounding this change was far more complex than they first appeared. The shift from a hospital-based nursing apprenticeship with its focus on craftlike attention to procedures and techniques, to the university educational model based on the development of life-long skills for problem-solving and self-directed learning as well as research awareness and critical analysis [1] highlighted different conceptions of teaching, as well as learning [5].

In addition, the degree-educated nurse is different from the traditional diploma graduate. The scope of nursing practice broadens from the individual person in the acute care, hospital setting to encompass the family and community from which they come. In addition to high levels of expertise in acute care, serious attention to primary care, health promotion and stabilization of chronic illnesses was added. An Bord Altranais [1] identifies the nurse as functioning across all settings both in formal agencies and in communities. Of course, the nurse is a major team member in the acute care general hospital. In the emerging future, this nurses' role adds all varieties of community settings such as community health centers, schools, senior centers. In fact, any place where the Irish people need health promotion, education to prevent disease and to stabilize chronic illnesses there is a place for the nurse. Critical thinking mechanisms facilitate the implementation of the new research-based practice contexts of nursing. In the same perspective, implementation of advanced biological and humanistic sciences moves nursing standards to 
more precise and more sophisticated levels. The legal and ethical components of nursing practice are expanded to include the evolutionary perspective of the nurse as client advocate. Implied in this advocacy role is an enormous development of insight regarding the ability of the nurse to engage in power and change in the healthcare system. The School's challenge was to take the broadly expanded outcomes as defined by An Bord Altranais and to operationalize them within a university curriculum.

\section{The Critically Thinking Nurse}

The first step in implementing the new nursing curriculum was to identify what the student was to achieve by the end of the program as a degree nurse graduate. For example, if we wanted the learner to think critically - a major goal and distinguishing feature of degree-level nursing - then the concept of critical thinking had to be infused both horizontally and vertically through the curriculum with increasing levels of difficulty and sophistication. Furthermore, the teaching staff needed a shared understanding of the critical thinking concept itself. Critical thinking is consonant with the scientific method, and so, the steps in definition should parallel the scientific method, for example, collecting data, identifying need or question, making a plan, testing the plan or implementation and assessing the outcome. Understanding that the traditional hospital school of nursing focused on procedures and treatments, abstract critical thinking was an entirely new phenomenon.

Critical thinking had to be used overtly by the teaching staff when talking about how nurses think in direct care practice. The nurse goes through each critical thinking step systematically. Hence, content is presented in the context of critical thinking, books are chosen for their critical thinking perspective and there is a logical internal consistency to the use of critical thinking across each year of the program of study. Content and principles from other disciplines such as science, psychology and sociology all are applied as part of supportive rational for care implementation beginning with the very early courses. For example, one of the learners' first assignments was based on critical thinking and the use of sociology in understanding patient need. Even at the novice level, students can and should be using sociological concepts of gender, social class and ethnicity in shaping insight into the patients' nursing care needs [6]. Granted the context and content will be basic, but the knowledge applied by the learner is higher order. Across the undergraduate program the scientific principles and the critical thinking generated can serve as valuable evidence in student portfolios for both summative and formative assessment $[7,8]$. In essence, research-based critical thinking serves as an important vehicle for outcomes assessment both for students and for program assessment as a whole.

\section{About Our Students}

The road to graduation has no single starting point for our students. They commence their journeys from many different places. Only some of our students have completed second level school. Some have studied sciences and some have not. The more mature students who tend not to have completed secondary school, bring life skills, experience and motivation to succeed [9]. Some of them have experience as care assistants. On the other hand, students straight out of second level school may appear more immediately able to deal with formal classroom and study expectations than their more mature counterparts who tend to be very unsure of their academic skills and prowess. To accommodate this heterogeneous group, the curriculum must commence at a very fundamental level. There is, however, a strong expectation that all students will "read" nursing as an academic discipline. This requires them to develop scholarly habits of self-directed learning which will stand them in good stead throughout their nursing careers as knowledge becomes outdated at an increasingly rapid rate. The challenge, then, is to encourage students to read nursing in ways that enable them to renew the nursing knowledge as required [10]. The term research-based practice acknowledges this ongoing application of current science. Reading a discipline's literature has long been the university's method of preparing the expert. This is the essence of the task for Nursing as it moves from apprenticeship training to university education. The new nurse is not taught everything. The new nurse is taught how to learn actively.

\section{When is the Student Ready for Active Learning?}

The question most often raised by staff in discussions of proposed curriculum development was 'When can students move towards active learning and higher level earning modes?' The answer was that the student can learn actively from the outset. The beginning student is ready and we should capitalize on their readiness to learn a new discipline. The longer they are allowed to be 'passive learners' the more difficult it is to shift them towards self-directed learning. Day one orientation highlights the generic skills the students develop along with an increasingly sophisticated understanding of subject matter. Focusing on skills related to group work, research, writing, information retrieval and assessment enable students to take control of their learning. These are skills for life-long learning which emphasize the sharing of control and will serve practicing nurses well as they share the locus of control regarding health with their clients. Whenever teachers model the shared control of learning with their students they effectively move the student towards the highest level of learning in the affective domain, that is, the value complex [11]. These value complex behaviors become an intrinsic part of the student nurses' developing professional repertoire of skills.

\section{Methods}

One of the most striking differences between hospital-based nurse education and the university situation is the difference in student numbers, class size, student-teacher ratios, and so, the methods used to teach [10]. In essence, this represents a move from training in relatively small groups to large group education. Another confounding factor is the move from a 52 week yearly calendar to the 30 week academic calendar. The traditional 
hospital-based teaching methods will not suffice. The tightening of the schedule and increased student numbers forced teachers and students into large lecture classes. How was the pressure to give lectures reconciled with the development of critical thinking? The lecture cannot be used to spoon feed all necessary information to students who in tum, copy it all down word for word and reproduce it in examinations [12]. The demand on the teacher is now to become the master teacher who teaches to the affective domain, that is, one who models the values of the profession and stimulates the learner's motivation to explore those values.

As a scholar, the teacher models the professional behavior of the discipline. This method transfers concepts and values and thus behaviors of how the professional nurse thinks, behaves and views nursing situations. This "engaged critical model of teaching" [13] aims to integrate the application of scientific principles with attention to the learner who responds on a higher level. Group projects reinforce the learning responsibilities of students and promote structured collaborate learning; tutorials provide opportunities for students to practice and shape their increasingly sophisticated mastery of content/subject matter. All of these changes in learning reflect the new environment of nursing in universities. The nursing profession is ready for a place where facilitation of learning overrides the mere transmission of information and the demonstration of procedures.

\section{Why Assess Outcomes?}

In curriculum discussions, a question frequently raised by our colleagues was, "Does auditing higher education outcomes against specific standards create masterpieces or paint by number, pedestrian programs?" Our response was always that it depends upon the standards under discussion. Therefore we needed to ensure the right standards were established and kept in mind that the standards were the measurable minimum standards of care. Thus the phrase, raising the standards, is the conscious goal of pushing upward the baselines of practice. Were we painting by numbers? Yes, we were, in the sense that clearly articulated standards are a minimum guide and there is nothing to prevent teachers and learners from exceeding them. It must be clear to both the teacher and the learner that a standard is the minimum learning or practice level to be reached and not the maximum level that we are working towards.

The goal is to reach the minimum (standard) and then to exceed it. It was absolutely essential that teachers and students understood that assessment is not solely about measuring content acquisition. The volume of content is so enormous on any nursing subject that it is not possible or desirable to know it all. Real education is facilitating and then measuring the integration of cognitive learning, value development and psycho-motor competencies as they are manifested in direct practice [11]. Bloom's Taxonomy was virtually unknown in Ireland when we started the project. Yes, it is important that nursing students know things, but that is not an end in itself. The real test of assessment is to measure whether students can take what they know and apply that knowledge in practice. This is why identification of learning outcomes is essential to answer the question, "What are the standards of care?" This is the reason why outcomes assessment is crucial in an educational plan. You have to know where you are going in order to be able to get there accurately, efficiently and effectively [7]

\section{Using Bloom's Taxonomy to Measure Outcomes}

Assessment tools, as with research tools, should be valid and reliable. An assessment tool must measure what it says it will measure and do so consistently. Bloom's Taxonomy of Educational Objectives (1956-64) is one such system of assessment which has existed and has been used internationally for forty years. This taxonomy, or list of verbs, defines actions across three domains of learning: cognitive, affective and psychomotor. These domains are particularly useful for nurse education where the cognitive skills required range from simple, basic recall of knowledge, through higher-order thinking, such as clinical decision-making. The affective domain ranges from merely receiving knowledge through to the development of complex professional value systems. And the psychomotor domain provides a systematic approach to development and assessment of standard nursing procedures. An Bord Altranais gave us the program outcomes for the new nursing scope of practice. Bloom's categories can be used to operationalize the program outcomes by creating courses or modules with clearly stated and measurable learning outcomes. If the learning outcomes are properly articulated it is quickly apparent that it is no longer appropriate to simply transfer knowledge from the teacher to the learner. This was a powerful rationale for the teachers to review their teaching, learning and assessment methods.

\section{Professional Development}

It was essential that all members of the teaching team begin the journey with a complete understanding of the destination desired, that is, they had to know what type of graduate they were trying to produce. The questions which had to be asked included what does this degree prepared nurse think, value and do? A systematic program of staff development workshops was used as a vehicle for answering the questions, moving the curriculum development process forward and polishing teaching skills. It was imperative for the teaching team to recognize that the conceptions of teaching and the teaching methods which served them well in hospital-based systems were inappropriate for university level education [5,12]. As professionals who pride themselves on their teaching expertise, the teachers modelled leadership by continually evolving their teaching practice in this new context. Making time for such professional development activities and having available some forms of structured program of support for these teachers proved invaluable.

A basic workshop series targeted specific aspects of the curriculum was very useful to refine program outcomes, to construct discrete courses and to measure outcomes. Each 
workshop was repeated a number of times over the course of several weeks, to enable maximum attendance. When exposed to new learning processes the nurse lecturers responded by sharing the workshop outcomes with their colleagues. As a result, new levels of informal and formal conversations emerged. This process was very important for us, in that it gave staff input to curriculum development but just as importantly, it challenged them to think about their conceptions of teaching and to share their values with colleagues openly. We found that this process was a very powerful method of getting staff to think more broadly about their teaching role in that the workshops focused on the curriculum as a whole, rather than individual teaching responsibilities [13-15].

\section{Conclusion}

In the new model leading to degree level nursing outcomes, the learner will have travelled in the vehicle of a carefully planned curriculum. The students' progress is mapped with clearly stated outcomes, tailored teaching and learning methods and measured by carefully planned assessments - both formative and summative - at various points progressively. The assessments are managed to ensure that both students and staff have appropriate feedback at key points that naturally fall in the program. Nurse tutors need support as they move from hospital to university settings. A staff development program which works in tandem with curriculum development ensures that the new lecturers have the necessary competencies to work in a scholarly environment and to prepare the student nurse for a more complex practice. The team of Fitzsimons and Huntley-Moore was successful in transitioning a complex (700 students) into a full-fledged collegiate model and today the Trinity College School of Nursing and Midwifery is ranked among the 25 world's best schools of nursing as cited by the World Rankings by subject. Dr. Fitzsimons replicated her success in curriculum design in Ireland by continuously serving as a Curriculum Consultant and lecturer to four additional colleges and universities in Ireland as recently as 2017.

\section{References}

1. An Bord Altranais (2005) Requirements and Standards for Nurse Registration Education Programmes ( $\left.2^{\text {nd }} E d n\right)$, An Bord Altranais, Dublin, Republic of Ireland.

2. Joel L (2013) Kelly's Dimensions of Professional Nursing. (10 $10^{\text {th }}$ Edn), McGraw Hill, New York, USA.

3. AACN (2016) FY 2017-2019 Strategic Plan Goals and Objectives.

4. (2005) Report of the Commission on Nursing: a blueprint for the future. Department of Health, Dublin, Republic of Ireland.

5. Prosser M, Trigwell K (2015) Understanding Learning and Teaching: the experience in higher education. SRHE \& OxfordUniversity Press, Buckingham, UK.

6. Hyde A Lohan M, McDonnell 0 (2004) Sociology for Health Professional in Ireland. Dublin University Press.

7. Huba ME, Freed JE (2000) Learner-Centered Assessment on College Campuses. Allyn and Bacon, Boston Massachusetts.

8. Knight P (2001) A Briefing on Key Concepts: Formative and Summative, Criterion and Norm-Referenced Asssessment. LTSN, England.

9. Fleming S, McKee G (2005) The mature student question. Nurse Education Today 25(3): 230-237.

10. Kenny G (2004) The tensions between education and models of nurse preparation. British Journal of Nursing 13 (2): 94-100.

11. Bloom BS, Krathwohl DR, Masia BB (1956-64) Taxonomy of Educational Objectives: the classification of educational goals. Longmans, London, England.

12. Bligh DA (2000) What's the Use of Lectures?. Jossey-Bass, San Francisco, USA.

13. Farrell A, Magenis S (2015) Teaching and learning activities: expanding the repertoire to support learning. In: O'Neill, G Moore S, McMullin $B$ (Eds.), Emerging Issues in the Practice of University Teaching and Learning. AISH, Dublin City University, Republic of Ireland.

14. Beach DJ (2002) Professional knowledge and its impact on nursing practice. Nurse Education in Practice 2(2): 80-86.

15. Brown EL (1950) Abstract for Action, National League for Nursing Press Buchan.

\section{Your next submission with Juniper Publishers will reach you the below assets}

- Quality Editorial service

- Swift Peer Review

- Reprints availability

- E-prints Service

- Manuscript Podcast for convenient understanding

- Global attainment for your research

- Manuscript accessibility in different formats

(Pdf, E-pub, Full Text, Audio)

- Unceasing customer service

Track the below URL for one-step submission https://juniperpublishers.com/online-submission.php 